\title{
DETERMINAN INDEKS PEMBANGUNAN BERKELANJUTAN DI 34 PROVINSI INDONESIA
}

\author{
Petrus Yudha Sasmita ${ }^{(1)}$, Restiatun ${ }^{(2)}$, dan Akhmad Yani ${ }^{(3)}$ \\ 1,2,3 Ilmu Ekonomi, Fakultas Ekonomi dan Bisnis, Universitas Tanjungpura \\ 1,2,3 Jalan Daya Nasional, Kel. Bansir Laut, Pontianak Tenggara, Kota Pontianak, Kalimantan Barat-78113 \\ E-mail: tovanyuzha@yahoo.com ${ }^{1)}$,restiatun@untan.ac.id ${ }^{2)}$, akhmad.yani@ekonomi.untan.ac.id ${ }^{3)}$
}

\begin{abstract}
ABSTRAK
Penerapan Sustainable Development Goals (SDGs) mengusung konsep no one left behind sebagai suksesor dari Millenium Development Goals (MDGs. Tujuan Pembangunan Berkelanjutan (TPB) pada negara berkembang seperti Indonesia adalah pemerataan pembangunan. Ketimpangan pencapaian pembangunan berkelanjutan di Indonesia di bidang ekonomi, sosial, maupun lingkungan. Identifikasi determinan yang optimal dalam meningkatkan pembangunan berkelanjutan di Indonesia menjadi penting sehingga diharapkan tujuan pembangunan berkelanjutan dapat tercapai dengan baik dan merata. Penelitian ini bertujuan menguji dan menganalisis faktor-faktor yang berpengaruh terhadap pembangunan berkelanjutan, baik dari pilar ekonomi, sosial, maupun lingkungan. Metode penelitian yang digunakan adalah regresi data panel. Data yang digunakan adalah indeks Produk Domestik Regional Bruto (PDRB), Indeks Pembangunan Manusia (IPM), Indeks Kualitas Air (IKA), Indeks Kualitas Udara (IKU), Indeks Kualitas Tutupan Lahan (IKTL), dan Indeks Pembangunan Berkelanjutan (IPB) 34 provinsi di Indonesia pada periode 2016-2019 dengan bentuk data tahunan. Hasil penelitian menunjukkan Indeks PDRB, IPM, IKA, IKU, dan IKTL berpengaruh terhadap IPB. Indeks pembangunan berkelanjutan di 34 Provinsi di Indonesia pada kegiatan pembangunan dapat meningkatkan kesejahteraan dan taraf hidup masyarakat melalui kebijakan pembangunan yang diambil oleh pemerintah. Indeks komposit mampu mengukur pencapaian pembangunan manusia berbasis sejumlah komponen dasar kualitas hidup. IKA, IKU, dan IKTL sebagai pencapaian hasil pengelolaan lingkungan hidup secara nasional. Pemerintah dan pemegang kebijakan agar dalam meningkatkan IPM harus melalui program pembangunan ekonomi hijau.
\end{abstract}

Kata Kunci: Indeks Pembangunan Manusia, Pembangunan Berkelanjutan, Indeks Kualitas Air

\section{PENDAHULUAN}

Pembangunan berkelanjutan merupakan suatu konsep yang menjadi prioritas negara-negara di dunia. Di Indonesia sebagai acuan agenda pembangunan nasional yang terdapat dalam NAWACITA pada masa pemerintahan Presiden Joko Widodo diterjemahkan dalam rencana pembangunan jangka menengah (RPJMN) 2015-2019 dan RPJMN 2020-2024. Program ini bertujuan untuk meningkatkan kesejahteraan masyarakat serta selaras dengan Tujuan Pembangunan Berkelanjutan (TPB) atau Sustainable Development Goals (SDGs) (Bappenas \& BPS, 2020; Rassanjani, 2018).

Perserikatan Bangsa-Bangsa (PBB) bersama dengan 194 negara, civil society, dan berbagai pelaku ekonomi dari seluruh penjuru dunia menyusun SDGs. Hal ini sebagai upaya dalam mengatasi kemiskinan, kesenjangan, dan perubahan iklim dalam bentuk aksi nyata dengan target tercapai pada tahun 2030. Tujuan dan target tersebut meliputi 3 (tiga) aspek yaitu ekonomi, sosial dan lingkungan (Humas, 2016).

Pemerintah Indonesia kembali menegaskan komitmennya dalam mendukung upaya pembangunan berkelanjutan untuk mengurangi dampak perubahan iklim. Mengurangi emisi gas rumah kaca sebesar $29 \%$ tanpa syarat (dengan usaha sendiri) dan $41 \%$ bersyarat (dengan dukungan internasional yang memadai) pada 2030 (Hartarto, 2021).

Ide dalam mengurangi dan memberantas kemiskinan sekaligus masalah-masalah terkait ekonomi, sosial dan lingkungan muncul pada pertengahan abad 20, di mana United Nations General Assembly memproklamasikan The Universal Declaration of Human Rights (UDHR) pada 10 Desember 1948 yang berisi tentang indikator umum pencapaian pembangunan bagi seluruh negara dan masyarakat di dunia. Kemudian, pada tahun 2000 Perserikatan Bangsa-Bangsa (PBB) mendeklarasikan Millenium Develompent Goals (MDGs) yang berisi delapan tujuan pembangunan yang ditargetkan akan tercapai pada tahun 2015 yang meliputi pemberantasan kemiskinan dan kelaparan ekstrem; pemberian pendidikan primer secara universal; meningkatkan kesetaraan gender dan pemberdayaan perempuan; menurunkan tingkat kematian anak; meningkatkan kesehatan ibu hamil; memerangi HIV/AIDS, malaria, dan penyakit lainnya; memastikan keberlangsungan lingkungan; dan kerja sama global dalam pembangunan (Bappenas, 2020). 
Pencapaian MDGs paling optimal pada wilayah kesehatan dan pendidikan, di mana pemberantasan kelaparan menunjukkan kemajuan yang baik, menurunkan kemiskinan ekstrem yang kesulitan dalam mengakses air bersih menjadi setengahnya, penurunan 200 juta jiwa yang tinggal di wilayah kumuh, pemberantasan penyakit menular seperti malaria dan HIV/AIDS serta penurunan angka kematian ibu dan bayi menunjukkan hasil yang baik, kesetaraan gender serta peningkatan iklim perdagangan (United Nations, 2013). Meskipun demikian, di antara masalah yang dihadapi MDGs adalah kesenjangan di mana pencapaian targettarget pembangunan tersebut tidak merata di seluruh dunia yang menunjukkan kesenjangan yang besar. Ancaman terbesar bagi pembangunan manusia merupakan konflik, di mana negara-negara terdampak konflik memiliki tingkat kemiskinan tertinggi di dunia.

Indonesia merupakan negara yang menarik untuk dikaji dari sisi pembangunan berkelanjutan, di mana wilayah Indonesia yang luas cenderung mengalami pembangunan yang tidak merata namun cenderung terpusat di wilayah sekitar ibu kota. Adapun provinsi yang mempunyai rencana aksi pembangunan berkelanjutan hanya sebanyak 19 provinsi dalam bentuk Rencana Aksi Daerah (RAD), yaitu Kalimantan Selatan, Gorontalo, Sulawesi Selatan, Bali, Nusa Tenggara Barat, Nusa Tenggara Timur, Sumatera Selatan, Sulawesi Tengah, Sulawesi Utara, Sumatera Barat, Riau, Bengkulu, Lampung, Jawa Barat, Jawa Tengah, Jawa Timur, Daerah Istimewa Yogyakarta, Kalimantan Utara, serta Kepulauan Riau. Adapun selebihnya belum selesai melakukan penyusunan RAD (Salsabila, 2019).

Kendala provinsi-provinsi yang belum memiliki RAD menurut Direktur Sinkronisasi Urusan Pemerintahan Daerah Kementerian Dalam Negeri, Suwignyo yaitu adanya perbedaan periode pemerintahan pada tiap daerah. Pada dasarnya SDGs perlu diimplementasikan pada Rencana Pembangunan Jangka Menengah Daerah (RPJMD), namun gubernur yang baru menjabat belum dilantik atau pilkada baru saja usai sehingga belum menyelesaikan RPJMD (Salsabila, 2019).

Beberapa penelitian terdahulu terkait SDGs di antaranya dilakukan oleh Swain \& Yang-Wallentin (2020) yang menemukan pilar sosial dan lingkungan adalah faktor paling efektif terhadap pembangunan berkelanjutan bagi negara maju, sementara pilar ekonomi dan sosial paling efektif terhadap pembangunan berkelanjutan bagi negara-negara berkembang. Adapun Pradhan menemukan SDG 1 (tidak ada kemiskinan) bersinergi dengan hampir seluruh SDGs lainnya, sementara SDG 12 (konsumsi dan produksi yang bertanggung jawab) adalah tujuan yang memiliki paling banyak trade-off dengan tujuan lainnya (Pradhan, Kroll, \& Wachold, 2017).

Kroll menemukan terdapat sinergi pada proyeksi SDGs khususnya pada SDG 1, 3, 7, 8, dan 9 yaitu penghapusan kemiskinan dan penguatan perekonomian, yang berakar pada inovasi, tetap menjadi basis dalam mencapai tujuan-tujuan pembangunan berkelanjutan lainnya (Kroll, Wachold, \& Pradhan, 2019). Adapun pada SDG 11, 13, 14, 16, dan 17 menunjukkan adanya trade-off dan minimnya keterkaitan dengan tujuan lainnya pada masa depan, yang menekankan perlunya penguatan inovasi dan kebijakan yang dapat membuat kota dan komunitas lebih berkelanjutan, serta penguatan institusi dan meningkatkan aksi penanganan perubahan iklim.

Penelitian ini bertujuan untuk menganalisis pengaruh pilar-pilar pembangunan berkelanjutan terhadap indeks pembangunan berkelanjutan di 34 provinsi di Indonesia untuk mengevaluasi pilar-pilar pembangunan berkelanjutan yang perlu diperkuat spesifik terhadap provinsi terkait (Beni, Manggu, \& Sadewo, 2020).

\section{RUANG LINGKUP}

Batasan-batasan masalah yang dibahas pada penelitian ini yaitu pilar ekonomi, sosial, dan lingkungan yang masing-masing diwakili oleh indeks PDRB per kapita, Indeks Pembangunan Manusia (IPM), dan Indeks Kualitas Lingkungan Hidup yang meliputi Indeks Kualitas Udara (IKU), Indeks Kualitas Air (IKA), dan Indeks Kualitas Tutupan Lahan (IKTL) sebagai variabel independen dan Indeks Pembangunan Berkelanjutan (IPB) sebagai variabel dependen. Objek yang diteliti adalah 34 provinsi di Indonesia pada tahun 2016-2019.

Berdasarkan batasan masalah di atas, maka permasalahan yang hendak diteliti pada penelitian ini yaitu apakah indeks PDRB per kapita, IPM, IKU, IKA, dan IKLH berpengaruh terhadap IPB di 34 provinsi di Indonesia.

Terdapat tiga pilar pendekatan pembangunan berkelanjutan yang terdiri dari ekonomi, sosial, dan lingkungan sebagaimana terlihat pada gambar 1 .

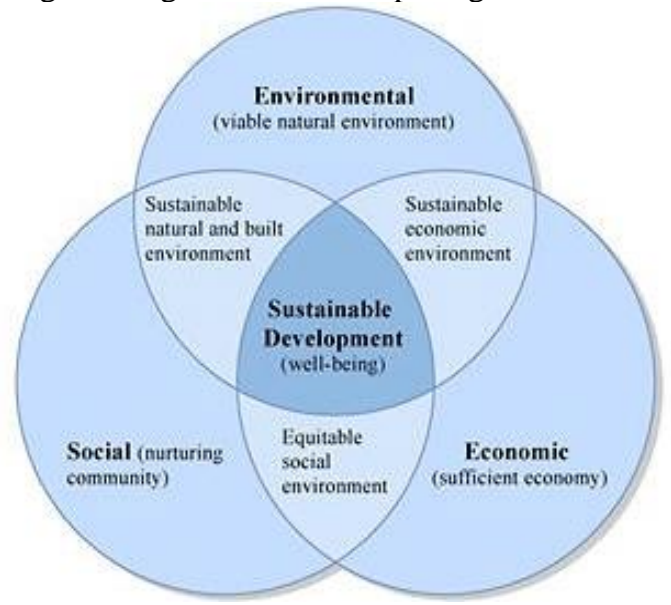

\section{Gambar 1. Pilar-Pilar Pembangunan Berkelanjutan}

Tiga pilar kerangka pembangunan berkelanjutan yang terdiri dari ekonomi, sosial, dan lingkungan saling mempengaruhi satu sama lain dan memerlukan sinergisme berbagai pihak untuk diwujudkan secara bersama-sama untuk kelanjutannya. Hal ini menjadi 
cukup sulit untuk dianalisis pada negara-negara berkembang, selain finansial yang umumnya kurang memadai, perlu kesadaran berbagai pemegang kebijakan terkait pembangunan berkelanjutan dan diimplementasikan dalam rencana kerja sehingga pembangunan berkelanjutan dapat diwujudkan dengan optimal. Terlebih pada negara dengan wilayah yang relatif luas dengan jumlah penduduk yang tinggi, seperti Indonesia.

Pembangunan berkelanjutan adalah proses pembangunan yang dilakukan dengan cara optimalisasi utilitas sumber daya alam (SDA) dan sumber daya manusia (SDM) secara serasi. Selain menitikberatkan pada isu lingkungan, pembangunan berkelanjutan juga mencakup tiga aspek atau pilar pembangunan berkelanjutan sebagaimana dalam laporan KTT dunia tahun 2005, yaitu ekonomi, sosial, dan lingkungan. Ketiga pilar tersebut saling memperkuat dan saling bergantung dalam mendorong pembangunan berkelanjutan.

Terdapat tiga pendekatan yang menjadi indikator pembangunan berkelanjutan, yaitu pembangunan yang ditujukan untuk menyetarakan kesejahteraan ekonomi, kesejahteraan sosial, serta pelestarian lingkungan dalam sistem pembangunan yang saling terkait (BPS, 2020). Tiga pilar tersebut merupakan acuan dalam interaksi pembangunan berkelanjutan dalam suatu sistem dengan tujuan mencapai dampak yang lebih baik dari tindakan atau keputusan manusia.

Pada dasarnya keberlanjutan secara umum dipahami sebagai kondisi yang memenuhi kebutuhan ekonomi dan sosial tanpa menghabiskan sumber daya alam dan kualitas lingkungan yang menjadi dasar bagi kesehatan, keamanan, dan kesejahteraan manusia (Beni, 2017).

Pembangunan berkelanjutan merupakan tujuan untuk mencapai kondisi tersebut sehingga dapat menguntungkan generasi saat ini serta generasi selanjutnya, serta proses di mana alat-alat, model, dan pendekatan inovatif digunakan untuk mendorong kemakmuran ekonomi seiring meminimalisasi dampak terhadap lingkungan dunia (Hecht dan Fiksel, 2014). Hubungan antar pilar-pilar pembangunan berkelanjutan dapat dilihat pada gambar 2 .

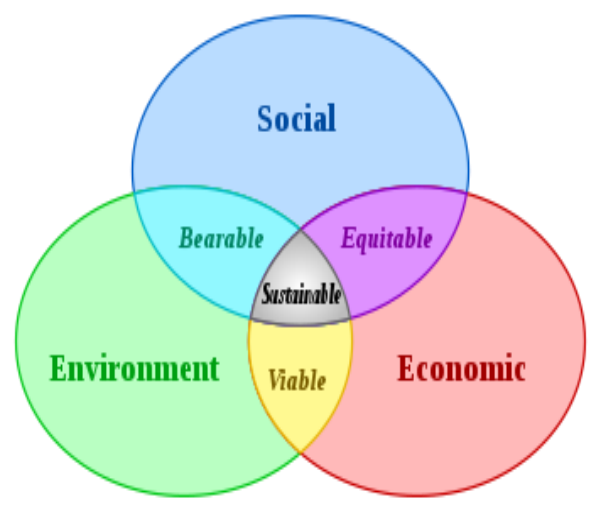

Gambar 2. Hubungan antar Pilar Pembangunan Berkelanjutan
Indikator pada pilar ekonomi meliputi pekerjaan, insentif, permintaan dan penawaran, perhitungan sumber daya alam, biaya,dan harga. Adapun pada pilar sosial yaitu keadilan lingkungan, kesehatan manusia, partisipasi, pendidikan, keamanan sumber daya, dan manajemen berkelanjutan. Pilar lingkungan meliputi pelayanan ekosistem, teknik dan bahan kimia yang berwawasan lingkungan, kualitas udara, kualitas air, tekanan, dan integritas sumber daya (Beni, Manggu, \& Sensusiana, 2018).

Pilar-pilar pembangunan berkelanjutan merupakan komponen yang dalam mencapainya memerlukan sinergitas dalam perumusan dan pengimplementasian strategi sehingga pilar-pilar pembangunan berkelanjutan dapat didirikan secara seimbang. Oleh karena itu komponen-komponen yang berada dalam pilar tersebut juga perlu ditingkatkan baik dari dimensi ekonomi, sosial, dan lingkungan. peningkatan kualitas sumber daya manusia berdampak pada pelaku ekonomi dapat menghasilkan komoditas dengan nilai tambah yang tinggi sehingga PDB dan pendapatan per kapita akan mengalami peningkatan pula. Dengan mengakomodir dampak terhadap lingkungan dalam kegiatan produksi serta pemanfaatan sumber daya alam, maka keberlangsungan alam akan terjaga. Hal ini secara kolektif akan meningkatkan kualitas manusia yang dilihat melalui tingginya indeks pembangunan manusia. Sumber daya manusia berkualitas dan berwawasan lingkungan serta pembangunan berkelanjutan akan memiliki peluang semakin tinggi dalam mencapai tujuan pembangunan berkelanjutan secara merata yang tergambar melalui indeks pembangunan berkelanjutan.

Kerangka model pemikiran pada penelitian ini dapat dilihat pada gambar 3 .

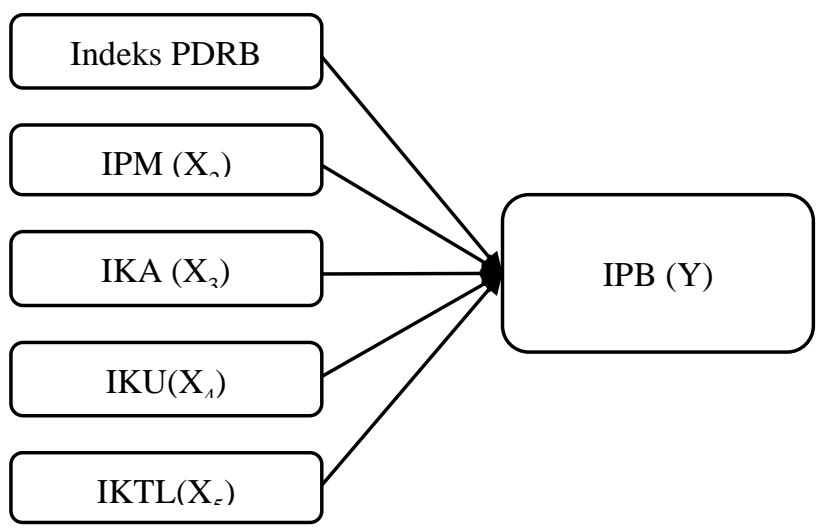

Gambar 3. Kerangka Model Pemikiran

\section{BAHAN DAN METODE}

Indeks PDRB merupakan indeks yang menggambarkan capaian perkembangan kesejahteraan masyarakat secara makro (Fauzi dan Oktavianus, 2014).

IPM merupakan indeks komposit dalam mengukur capaian pembangunan manusia berbasis sejumlah komponen dasar kualitas hidup (umur panjang dan hidup 
sehat, pengetahuan, dan standar hidup layak) (UNDP, 2020).

IKA, IKU, dan IKTL merupakan indeks yang menggambarkan kondisi dari hasil pengelolaan lingkungan hidup secara nasional (Kementerian Lingkungan Hidup dan Kehutanan Republik Indonesia, 2019).

IPB merupakan indeks komposit yang membentuk indikator pembangunan berkelanjutan yang lebih komprehensif baik dari perspektif ekonomi, sosial, dan lingkungan (Fauzi dan Oktavianus, 2014).

Berdasarkan jenis data dan analisis, penelitian ini menggunakan pendekatan kuantitatif untuk menguji dan menganalisis pengaruh Indeks PDRB, IPM, IKA, IKU dan IKTL terhadap IPB di 34 provinsi di Indonesia sehingga dapat diidentifikasi pilar-pilar yang memerlukan penguatan spesifik terhadap provinsi yang memerlukannya.

Berikut merupakan hipotesis pada penelitian ini:

$\mathrm{H}_{1}$ : Indeks PDRB berpengaruh terhadap IPB di 34 provinsi di Indonesia

$\mathrm{H}_{2}$ : IPM berpengaruh terhadap IPB di 34 provinsi di Indonesia

$\mathrm{H}_{3}$ :IKA berpengaruh terhadap IPB di 34 provinsi di Indonesia

$\mathrm{H}_{4}$ :IKU berpengaruh terhadap IPB di 34 provinsi di Indonesia

$\mathrm{H}_{5}$ :IKTL berpengaruh terhadap IPB di 34 provinsi di Indonesia

Data sekunder yang digunakan berbentuk data panel yang meliputi data pendapatan per kapita, Indeks Pembangunan Manusia (IPM), IKA, IKU, dan IKTL 34 provinsi di Indonesia pada periode 2016-2019. Data pendapatan per kapita dan IPM diperoleh melalui publikasi Badan Pusat Statistik, sementara IKLH diperoleh melalui publikasi Kementerian Lingkungan Hidup dan Kehutanan.

Tahapan analisis statistik pada penelitian ini meliputi pemilihan metode regresi data panel, regresi data panel, dan uji asumsi klasik (Hidayat, 2014). Berikut merupakan persamaan yang digunakan pada penelitian ini (1).

$$
\begin{gathered}
I P B_{i t}=\beta_{0}+\beta_{1} I P D R B_{i t}+\beta_{2} I P M_{i t}+\beta_{3} I K A_{i t}+\beta_{4} I K U_{i t}+ \\
\beta_{5} I K T L_{i t}+\varepsilon_{i t}
\end{gathered}
$$

Dimana $\beta_{0}$ pada (1) merupakan konstanta/intercept, $\varepsilon$ merupakan error term, $i$ merupakan provinsi, $t$ adalah tahun, dan $\beta_{(1-5)}$ merupakan koefisien masing-masing variabel independen.

\section{PEMBAHASAN}

Hasil dan pembahasan dalam penelitian ini dapat uraikan sebagai berikut:

\subsection{Hasil Pengolahan Data Penelitian}

Dalam penelitian ini dapat disajikan hasil pengolahan data berdasarkan beberapa uji, antara lain: hasil uji pemilihan model regresi panel berdasarkan Uji Chou dapat dilihat pada tabel 1 .

Tabel 1. Hasil Uji Chou

\begin{tabular}{|l|l|l|}
\hline Uji Efek & Koef. & Prob. \\
\hline Cross-section F & 1,247 & 0,203 \\
\hline Cross-section Chi Square & 48,102 & 0,043 \\
\hline
\end{tabular}

Berdasarkan probabilitas cros-section chi square sebesar 0,043 yang lebih kecil pada taraf signifikansi $5 \%$, maka $\mathrm{H}_{\mathrm{a}}$ diterima, model yang lebih tepat digunakan adalah fixed effect. Hasil uji pemilihan model regresi panel berdasarkan Uji Hausman probabilitas sebesar 0,077 lebih besar daripada taraf signifikansi 5\% sehingga $\mathrm{H}_{0}$ diterima, model yang lebih tepat digunakan adalah random effect.

Untuk menentukan model yang dipilih antara common effect atau common effect, dilakukan uji Lagrange Multiplier (LM Test) di mana hasil uji Lagrange Multiplier dengan probabilitas sebesar 0,6688 dengan koefisien 0,183 , di mana probabilitas lebih besar daripada taraf signifikansi $5 \%$ sehingga $\mathrm{H}_{0}$ diterima, model yang lebih tepat digunakan adalah common effect.

Berdasarkan hasil regresi panel pada tabel 2 menunjukkan hasil estimasi model dengan common effect model:

Tabel 2. Regresi Panel (Common Effect Model)

\begin{tabular}{|c|c|c|c|}
\hline Uji Variabel & Koef. & t statistik & Prob. \\
\hline$C$ & $-0,344$ & $-1,203$ & 0,231 \\
\hline$I P D R B$ & 0,167 & 449,908 & 0,000 \\
\hline$I P M$ & 0,502 & 153,331 & 0,000 \\
\hline$I K A$ & 0,010 & 150,006 & 0,000 \\
\hline$I K U$ & 0,102 & 53,7965 & 0,000 \\
\hline$I K T L$ & 0,133 & 154,284 & 0,000 \\
\hline
\end{tabular}

Berdasarkan tabel 2, persamaan yang terbentuk yaitu sebagai berikut (2):

$$
\begin{gathered}
I P B_{i t}=-0,344+0,167 I P D R B_{i t}+0,502 I P M_{i t}+ \\
0,010 I K A_{i t}+0,102 I K U_{i t}+0,133 I K T L_{i t}+\varepsilon_{i t}
\end{gathered}
$$

Interpretasi koefisien persamaan regresi pada persamaan (2) yaitu Ketika IPDRB, IPM, IKA, IKU, dan IKTL bernilai nol maka IPB bernilai -0,344, ketika IPDRB meningkat sebesar 1\%, maka IPB juga akan meningkat sebesar $0,167 \%$, ketika IPM meningkat sebesar 1\%, maka IPB juga akan meningkat sebesar $0,502 \%$ ketika IKA meningkat sebesar $1 \%$, maka IPB juga akan meningkat sebesar 0,010\%, ketika IKU meningkat sebesar $1 \%$, maka IPB juga akan meningkat sebesar $0,102 \%$, dan ketika IKTL meningkat sebesar $1 \%$, maka IPB juga akan meningkat sebesar $0,133 \%$ dengan asumsi cateris paribus. 
Nilai koefisien menunjukkan dampak peningkatan IPB terbesar terjadi ketika IPM meningkat sebesar $1 \%$. Hal ini mengindikasikan di antara pilar yang paling efisien dalam meningkatkan IPB adalah dengan meningkatkan IPM sehingga diharapkan pembangunan manusia yang optimal dapat memanfaatkan lingkungan dengan efisien dan berkelanjutan pula.

Nilai probabilitas t statistik pada tabel 2 yang lebih kecil daripada taraf signifikansi 5\% menunjukkan variabel Indeks PDRB, IPM, IKA, IKU, dan IKTL berpengaruh secara parsial terhadap IPB.

Uji koefisien determinasi menunjukkan kemampuan variabel-variabel independen dalam menjelaskan variasi dari variabel dependen dengan nilai adjusted $R^{2}$ sebesar
0,99 menunjukkan variabel Indeks PDRB, IPM, IKA, IKU, dan IKTL mampu menjelaskan $99 \%$ variasi dari IPB. Selebihnya (1\%) dijelaskan oleh variabel lain di luar model.

Hasil uji kelayakan model nilai probabilitas sebesar $0,000<0,05$ sehingga $\mathrm{H}_{\mathrm{a}}$ diterima dan $\mathrm{H}_{0}$ ditolak, Indeks PDRB, IPM, IKA, IKU, dan IKTL secara simultan berpengaruh terhadap IPB. Disimpulkan model pada penelitian ini layak diterima.

Uji asumsi normalisasi dilakukan untuk menguji apakah residual data berdistribusi normal atau tidak. Hasil uji normalisasi dapat dilihat pada gambar 3.

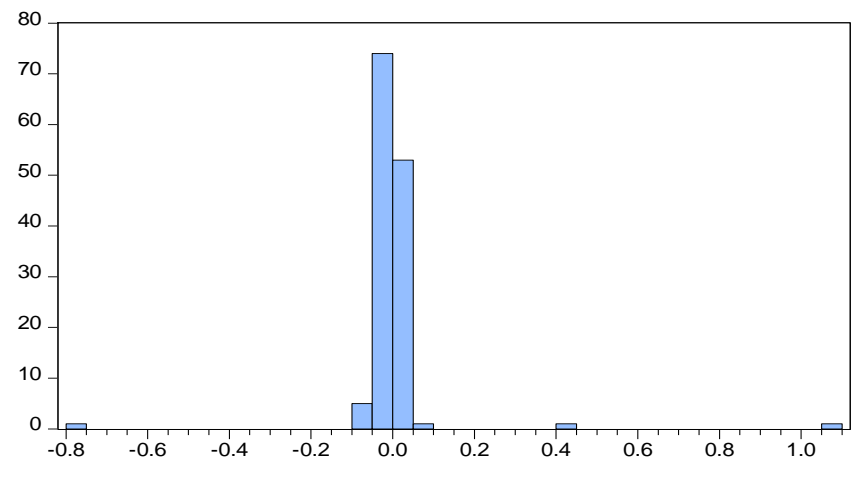

\begin{tabular}{|lc}
\hline \multicolumn{2}{|l}{ Series: Standardized Residuals } \\
Sample 2016 2019 \\
Observations & 136 \\
& \\
Mean & $-2.17 \mathrm{e}-14$ \\
Median & -0.003435 \\
Maximum & 1.074938 \\
Minimum & -0.782277 \\
Std. Dev. & 0.121688 \\
Skewness & 3.437706 \\
Kurtosis & 59.19015 \\
& \\
Jarque-Bera & 18159.42 \\
Probability & 0.000000
\end{tabular}

Gambar 3. Uji Normalisasi

Gamber 3 menunjukkan hasil uji normalisasi residual, di mana probabilitas sebesar 0,000 lebih kecil daripada taraf signifikansi $5 \%$ sehingga $\mathrm{H}_{\mathrm{a}}$ diterima, model tidak mengikuti distribusi normal. Berdasarkan Central Limit Theorem, apabila observasi memadai (lebih dari 30 observasi) maka asumsi normalisasi dapat diabaikan.

Selanjutnya, dilakukan uji multikolinieritas untuk menguji hubungan antar variabel bebas sebagaimana terlihat pada tabel 3 .

Tabel 3. Uji Multikolinieritas

\begin{tabular}{|c|c|c|c|c|c|}
\hline & IPPK & IPM & IKA & IKU & IKTL \\
\hline IPPK & 1 & 0.357 & -0.060 & -0.366 & -0.044 \\
\hline IPM & 0.357 & 1 & -0.136 & -0.337 & -0.481 \\
\hline IKA & -0.060 & -0.136 & 1 & 0.272 & 0.201 \\
\hline IKU & -0.366 & -0.337 & 0.272 & 1 & 0.489 \\
\hline IKTL & -0.0435 & -0.481 & 0.201 & 0.489 & 1 \\
\hline
\end{tabular}

Hasil uji multikolinieritas pada tabel 3 menunjukkan tidak terdapat variabel independen yang memiliki korelasi tinggi (lebih dari 0,8) sehingga disimpulkan model tidak mengalami gejala multikolinieritas.

\subsection{Analisis Faktor-faktor yang berpengaruh}

terhadap pembangunan berkelanjutan

Indeks PDRB, IPM, IKA, IKU, IKTL berpengaruh terhadap IPB mengacu pada teori-teori ekonomi bahwa tujuan utama kegiatan pembangunan adalah meningkatkan kesejahteraan dan taraf hidup masyarakat melalui kebijakan pembangunan yang diambil oleh pemerintah sesuai dengan teori Haror-Domar. (Todaro, Michael, \& Stephen C Smith, 2006).

Berdasarkan hasil uji korelasi juga dijelaskan bahwa semua indeks kualitas lingkungan berpengaruh positif terhadap pemenuhan kebutuhan dasar. Hal ini berarti bahwa jika terjadi kenaikan kualitas udara, tutupan lahan, kualitas air, kesehatan lingkungan, kesehatan masyarakat, dan keanekaragaman hayati maka pemenuhan kebutuhan dasar akan meningkat, begitu juga sebaliknya.

Indeks kualitas udara dan tutupan lahan mempunyai konstanta yang paling besar di antara indeks lainnya. Artinya, kenaikan dari nilai tersebut akan berdampak sangat besar pada kenaikan pemenuhan dasar. begitu juga sebaliknya, apabila indeks kualitas udara dan tutupan lahan mengalami penurunan, maka pemenuhan kebutuhan dasar masyarakat juga akan menurun.

Penduduk suatu negara memiliki hubungan yang sangat kuat dengan kesejahteraan mengingat penduduk adalah subjek dan objek dari pembangunan tersebut. Penduduk sebagai input sekaligus tujuan pembangunan dalam proses produksi untuk ditingkatkan kesejahteraannya. Kebijakan-kebijakan yang dilakukan oleh pemerintah daerah sangat menentukan akselerasi pembangunan ekonomi yang tentunya sangat 
memberikan dampak pada peningkatan kesejahteraan masyarakat.

Sedangkan, Indeks Pembangunan Manusia (IPM) menyadarkan kita akan arti pembangunan dalam arti luas, yakni pada dimensi kesehatan dan pendidikan yang juga merupakan tujuan pembangunan yang fundamental. Suatu negara yang memiliki penduduk dengan pendapatan tinggi, tetapi memiliki tingkat pendidikan yang rendah, tingkat kesehatan yang rendah sehingga berdampak pada angka harapan hidup yang rendah dari penduduk negara yang tingkat pembangunan yang lebih tinggi.

\section{KESIMPULAN}

Kesimpulan hasil penelitian di atas, dapat disimpulkan Determinan Indeks PDRB, IPM, IKA, IKU, dan IKTL berpengaruh terhadap IPB di 34 Provinsi di Indonesia. Pengaruh terbesar terjadi pada variabel IPM, di mana pilar yang paling efisien dalam meningkatkan IPB adalah dengan meningkatkan IPM. Hal ini berdampak pada pembangunan manusia yang optimal dapat memanfaatkan lingkungan dengan efisien yang berkelanjutan.

\section{SARAN}

Keterbatasan penelitian ini menggunakan data kuantitatif yang diuji dengan regresi data panel. Saran bagi peneliti selanjutnya akan menggunakan data kualitatif berupa pembangunan berkelanjutan terutama melalui program pembangunan ekonomi hijau. Sehingga pembahasan lebih detail dalam analisis ekonomi. Bagi pemerintah dan pemegang kebijakan agar dalam meningkatkan IPM harus selaras serta mengimplementasikan tujuan pembangunan berkelanjutan. Hal ini bermanfaat untuk mewujudkan pembangunan manusia melalui sinergi pilar-pilar pembangunan berkelanjutan.

\section{DAFTAR PUSTAKA}

Bappenas. (2020). Pedoman Penyusunan Rencana Aksi Tujuan Pembangunan Berkelanjutan (TPB)/Sustainable Development Goals (SDGs). Jakarta. Retrieved from http://sdgs.bappenas.go.id/wpcontent/uploads/2020/10/Buku-Pedoman-RencanaAksi-SDGs.pdf

Bappenas, \& BPS. (2020). SDGs Dashboard. Retrieved from

http://sdgs.bappenas.go.id/dashboard/\#!/pages/landin gPage.html

Beni, S. (2017). Pembangunan Manusia Melalui Pendidikan Dasar Credit Union. (Herulono, Ed.). Jakarta: Mer-C Publishing.

Beni, S., Manggu, B., \& Sadewo, Y. D. (2020). Pengaruh Denda Pajak Kendaraan Bermotor Terhadap Perilaku Taat Pajak. Borneo Akcaya, 6(1), 43-57.

Beni, S., Manggu, B., \& Sensusiana. (2018). Modal
Sosial Sebagai Suatu Aspek Dalam Rangka Pemberdayaan Masyarakat. JURKAMI, 3(1), 8-24. Retrieved from http://jurnal.stkippersada.ac.id/jurnal/index.php/JPE/a rticle/view/341

BPS. (2020). Indikator Tujuan Pembangunan Berkelanjutan Indonesia 2020. Jakarta. Retrieved from

https://www.bps.go.id/publication/2020/12/17/7a6c6a d8f95681d0050e7d89/indikator-tujuan-

pembangunan-berkelanjutan--tpb--indonesia2020.html

Hartarto, A. (2021). Pembangunan Berkelanjutan Menjadi Kunci Pemulihan Ekonomi Pasca Pandemi. Retrieved from https://www.ekon.go.id/publikasi/detail/3037/menkoairlangga-pembangunan-berkelanjutan-menjadikunci-pemulihan-ekonomi-pasca-pandemi

Hidayat, A. (2014). Im 744. Retrieved from https://www.statistikian.com/2014/11/regresi-datapanel.html

Humas. (2016). Tujuan Pembangunan Berkelanjutan. Retrieved from https://www.ojk.go.id/sustainablefinance/id/publikasi/prinsip-dan-kesepakataninternasional/Pages/Tujuan-PembangunanBerkelanjutan.aspx

Kroll, C., Wachold, A., \& Pradhan, P. (2019). Are we Successful in turning trade-offs into synergies? Palgrave Communications, 5(1), 1-11.

Pradhan, P., Kroll, C., \& Wachold, A. (2017). A Systemmatic Study of Sustainable Development Goal (SDG) Interactions. Earth's Future, 5(1), 69-72.

Todaro, Michael, P., \& Stephen C Smith. (2006). Pembangunan Ekonomi (9th ed.). Jakarta: Erlangga.

Rassanjani, S. 2018. Sustainable Development Goals (SDGs) and Indonetian Housing Policy. Jurnal Ilmu Pemerintahan, 8(1), hal. 44-55.

Salsabila, P. 2019. Baru 19 Provinsi yang Miliki Rencana Aksi Pembangunan Berkelanjutan, Bisnis.com. Tersedia pada: https://ekonomi.bisnis.com/read/20190502/45/91772 9/baru-19-provinsi-yang-miliki-rencana-aksipembangunan-berkelanjutan (Diakses: 21 Maret 2021).

Swain, R. B. dan Yang-Wallentin, F. 2020, Achieving sustainable development goals: predicaments and strategies. International Journal of Sustainable Development \& World Ecology, 27(2), hal. 96-106.

Todaro, Michael, P., \& Stephen C Smith. (2006). Pembangunan Ekonomi (9th ed.). Jakarta: Erlangga.

UNDP 2020. Human Development Index (HDI), Human Development Reports. Tersedia pada: http://hdr.undp.org/en/content/human-developmentindex-hdi.

United Nations 2013. The Millenium Development Goals Report 2013. New York. 